\title{
REVOLVING DOOR PHENOMENON AND RELATED FACTORS IN SCHIZOPHRENIA, BIPOLAR AFFECTIVE DISORDER AND OTHER PSYCHOTIC DISORDERS
}

\author{
Buket Koparal $^{1}$, Mehmet Ünler ${ }^{2}$, Hayriye Çisem Utku ${ }^{2}$ \& Selçuk Candansayar ${ }^{2}$ \\ ${ }^{I}$ Recep Tayyip Erdoğan University Training and Research Hospital, Psychiatry Clinic, Rize, Turkey \\ ${ }^{2}$ Gazi University Medicine Faculty Department of Psychiatry, Ankara, Turkey
}

received: 20.10.2020;

revised: 10.3.2021;

accepted: 18.3 .2021

\section{SUMMARY}

Background: Patients with chronic mental illness are frequently hospitalized and discharged from psychiatry wards. This situation is referred to as the "revolving door phenomenon" (RDP). In addition to factors related to the patient and the disease, limited number of beds leading to shortened hospital stay are among the reasons associated with frequent hospitalization. This study aims to compare patients with RDP and patients with single hospitalization in terms of clinical, sociodemographic, and treatmentoriented characteristics in order to evaluate the risk factors causing frequent hospitalization.

Subjects and methods: In this study, patients who were admitted and hospitalized between May 1, 2011 - May 1, 2016 were retrospectively evaluated from patient records. The RDP group consisted of 74 patients and the single-hospitalization group consisted of 59 patients who met inclusion criteria.

Results: The RDP group had significantly higher rates of male gender, ECT history, past suicide attempts, multiple drug treatment, clozapine use, legal incidents, and noncompliance to follow up following discharge compared to the single-hospitalization group $(p<0.05)$.

Conclusion: This study demonstrates that Turkey also has RDP patients with characteristics and hospitalization patterns similar to patients in countries with different cultural, social, and economic conditions. It is important to identify and correct factors that cause frequent hospitalization as it will reduce the burden of the health system as well as provide benefit to the patient.

Key words: schizophrenia - revolving door phenomenon - recurrent hospitalization

\section{INTRODUCTION}

Diseases such as schizophrenia, schizoaffective disorder, all the remaining psychotic disorders, likewise bipolar affective disorder are often chronic and display frequent relapses and remissions. There is one group of patients with chronic mental diseases who are frequently hospitalized and discharged from psychiatric wards. This patient group with frequent hospitalizations is described as the "revolving door phenomenon" (RDP). RDP first emerged after the discharge of psychiatric patients from hospitals due to population-based approaches (Gastal et al. 2000). The phenomenon has various definitions according to different authors. While some authors define RDP as 3-4 hospitalizations within 5-10 years, others refer to the same number of hospitalizations within a shorter period, like 2 years (Lichtenberg et al. 2008, Oyffe et al. 2009, Kastrup 1987, Lewis \& Joyce 1990). On the other hand, Botha and colleagues modified the RDP criteria proposed by Weiden and Glazer and created criteria such as three or more hospitalizations in 18 months or two or more hospitalizations in 12 months in the presence of clozapine use (Botha et al. 2010, Weiden \& Glazer 1997).

While RDP has been associated with several factors, the leading factors are still controversial. Frequent hospitalization is found to be associated with severity, natural course, and chronicity of the disease (Gastal et al. 2000; Korkeila et al. 1998; Lay et al. 2006; Roick et al. 2004). In addition to disease-related factors, patientrelated factors are also thought to be related to frequent hospitalizations, such as poor social support, low education level, and living alone (Lay et al. 2006; Gastal et al. 2000; Botha et al. 2010). Among this group of patients, the most significant variables for frequent hospitalizations were non-compliance to treatment (Goodpastor \& Hare 1991, Weiden \& Glazer 1997), tendencies to violence, suicidality (Di Lorenzo et al. 2016), and alcohol-substance abuse (Romer Thomsen et al. 2018, Weiden \& Glazer 1997, Kim et al. 2011). According to many researchers, the presence and length of previous hospital stays were also significant predictors of recurrent hospitalizations (Gültekin et al. 2013a, Frick et al. 2013, Montgomery \& Kirkpatrick 2002, Moss et al. 2014).

Different countries report similar causes for frequent hospitalizations. For example, one study conducted in Italy indicated that frequent hospitalizations were more prevalent among young, single, and unemployed people with poor social support (Morlino et al. 2011). Another study conducted in Germany found that low functionality, low education level and referral to a general practitioner after discharge were associated with frequent hospitalizations (Frick et al. 2013). One South 
African study reported that factors such as the history of substance abuse, disease severity, and premature discharges were more prevalent among patients with frequent hospitalizations. The limited number of hospital beds, leading to shortened hospitalization time, and therefore discharge without complete recovery cause frequent hospitalizations (Botha et al. 2010).

Contrary to the patient group with frequent hospitalizations, there is also a patient group with a relatively low number of hospitalizations despite long disease duration. Studies have reported that these patients have milder disease severity, treatment compliance and affective disorder diagnoses, although studies on this topic are not fully clear (Botha et al. 2010, Morlino et al. 2011).

Although some studies have researched the revolving door phenomenon in Turkey (Gültekin et al. 2013a,b, Aydın et al. 2014), we have not encountered a long-term study that compared RDP patients to singlehospitalization $(\mathrm{SH})$ patients.

At this work, we wanted to investigate the revolving door phenomenon in a clinic with the opportunity of long-term follow-up with mainly a population of patients with social security in Turkey. This study aims to retrospectively evaluate the risk factors of frequent hospitalizations and compare the clinical, sociodemographic, and treatment-related characteristics of RDP patients to SH patients. In RDP patients, we hypothesized that more non-compliance with outpatient clinic follow-ups, involuntary hospitalization, a tendency to violence, multiple drug use, and more intense substance use, and also less hospital stay.

\section{SUBJECT AND METHODS}

The current study was a retrospective study conducted at the Gazi University School of Medicine Psychiatric Inpatient Clinic in Ankara. The clinic consists of two open services with a total of 31 beds, serving patients from Ankara and its surroundings. The patient records between May 1, 2011, and May 1, 2016 were evaluated until January 1, 2018. Patients between the ages of 18 and 65 who were hospitalized and diagnosed with schizophrenia, schizophreniform disorder, schizoaffective disorder, acute and temporary psychotic disorder, delusional disorder, non-organic psychotic disorder, or bipolar affective disorder according to ICD-10 diagnostic criteria were included in the study. Among all patients, a total of 1209 hospitalizations and 965 patients with these diagnoses were identified. The RDP criteria were determined according to the modified criteria of Botha et al (Botha et al. 2010):

- $\geq 3$ hospitalizations in a 18-month period or,

- $\geq 2$ hospitalizations in a 12-month period and treated with clozapine or,

- $\geq 2$ hospitalizations in a 12-month period and a hospitalization period longer than 120 days.
The patients who received inpatient treatment only once during the current study period were included in the SH group. If there was not enough data in the patient file or the patient's diagnosis is uncertain, they were excluded from the study. A hundred and nine patients who met the RDP criteria were identified. Among these patients, 35 patients were excluded from the study due to inadequate data, for a total of 74 patients comprising the RDP group.

The screening identified 259 patients with singlehospitalization (SH). In this group, 200 patients were also excluded from the study due to inadequate data. A total of 59 patients met $\mathrm{SH}$ criteria.

Following the patient screening, a database consisting of sociodemographic characteristics (age, marital status, employment status, education level, place of residence), clinical data (history of substance use, psychiatric comorbidity, other medical diseases, family history of the psychiatric disease, age of onset, the total number of hospitalizations, the average length of stay in the hospital, type of hospital admission, compliance with follow up, reason for hospitalization, suicidal attempts, the tendency to violence, forensic events, disability pension, ICD-10 diagnoses), and treatment-related data (drugs used, ECT, depot drug use, side effects of drugs, chemical restraint) which may be related to the number of hospitalizations was formed. Suicide attempts were considered as "situations in which a person performs a life-threatening behavior with the intent of jeopardizing his or her life or to give the appearance of such intent" (da Graça Cantarelli et al. 2014). Judicial prosecution for the patient for committing a crime was considered as a forensic event. Side effects of drugs reported by the patient or their relatives or detected during the examination by the doctor were obtained from electronic patient records. Hospitalization without the consent of the patient, at the request of his/her family, was considered involuntary hospitalization, and the referral of the patient to hospitalization by the courts was considered as judicial hospitalization.

The study received ethics approval from the Gazi University School of Medicine Ethics Committee.

Categorical data were expressed as percentages and frequency; mean value \pm standard deviations and median values (minimum-maximum) of continuous variables were calculated. For each sample group and comparison of variables, the $\chi^{2}$ test was conducted for categorical data and the t-test for continuous data. Post-hoc analyses were applied in multiple groups. The logistic regression analysis was performed to evaluate prognostic factors predicting frequent hospitalization.

\section{RESULTS}

Sociodemographic data of the patients are presented in Table 1. The RDP group had significantly higher rates of male gender compared to the SH group $\left(\chi^{2}=11.181\right.$, $\mathrm{p}<0.01$ ). There was no statistically significant difference between the two groups according to age, marital status, 
Table 1. Sociodemographic characteristics of the groups

\begin{tabular}{|c|c|c|c|c|}
\hline & $\begin{array}{c}\text { Single } \\
\text { hospitalization N (59) } \\
\text { N (\%) }\end{array}$ & $\begin{array}{c}\text { Revolving door } \\
\text { phenomenon N (73) } \\
\text { N (\%) }\end{array}$ & $\begin{array}{c}\text { Total } \\
\mathrm{N}\end{array}$ & $P$ \\
\hline $\begin{array}{l}\text { Gender } \\
\text { Female } \\
\text { Male }\end{array}$ & $\begin{array}{l}34(57.6) \\
25(42.4)\end{array}$ & $\begin{array}{l}21(28.8) \\
52(71.2)\end{array}$ & $\begin{array}{l}55(41.7 \%) \\
77(58.3 \%)\end{array}$ & $<0.001$ \\
\hline $\begin{array}{l}\text { Marital status } \\
\text { Married } \\
\text { Single } \\
\text { Divorced } \\
\text { Widowed }\end{array}$ & $\begin{array}{c}23(39) \\
28(47.5) \\
7(11.9) \\
1(1.7)\end{array}$ & $\begin{array}{c}21(28.8) \\
34(46.6) \\
18(24.7) \\
0\end{array}$ & $\begin{array}{c}44(33.3 \%) \\
62(47 \%) \\
25(18.9 \%) \\
1(0.8 \%)\end{array}$ & 0.166 \\
\hline $\begin{array}{l}\text { Education level } \\
\text { Illiterate } \\
\text { Literate } \\
\text { Primary } \\
\text { Middle school } \\
\text { High school } \\
\text { Graduate }\end{array}$ & $\begin{array}{c}2(3.6) \\
3(5.5) \\
11(20) \\
7(12.7) \\
12(21.8) \\
20(36.4)\end{array}$ & $\begin{array}{c}1(1.4) \\
0 \\
10(13.9) \\
11(15.3) \\
27(37.5) \\
23(31.9)\end{array}$ & $\begin{array}{c}3(2.4 \%) \\
3(2.4 \%) \\
21(16.5 \%) \\
18(14.2 \%) \\
39(30.7 \%) \\
43(33.9 \%)\end{array}$ & 0.150 \\
\hline $\begin{array}{l}\text { Employment } \\
\text { Unemployed } \\
\text { Employed } \\
\text { Retired } \\
\text { Student }\end{array}$ & $\begin{array}{l}33(55.9) \\
10(16.9) \\
10(16.9) \\
6(10.2)\end{array}$ & $\begin{array}{l}40(54.8) \\
14(19.2) \\
16(21.9) \\
3(4.1)\end{array}$ & $\begin{array}{c}73(55.3 \%) \\
24(18.2 \%) \\
26(19.7 \%) \\
9(6.8 \%)\end{array}$ & 0.520 \\
\hline $\begin{array}{l}\text { Residence } \\
\text { Urban } \\
\text { Rural }\end{array}$ & $\begin{array}{c}56(96.6) \\
2(3.4)\end{array}$ & $\begin{array}{c}65(89) \\
8(11)\end{array}$ & $\begin{array}{l}121(92.4) \\
10(7.6 \%)\end{array}$ & 0.108 \\
\hline $\begin{array}{l}\text { Living companions } \\
\text { Family } \\
\text { Alone } \\
\text { Nursing home } \\
\text { Homeless } \\
\text { With friends }\end{array}$ & $\begin{array}{c}56(94.9) \\
2(3.4) \\
0 \\
0 \\
1(1.7)\end{array}$ & $\begin{array}{c}68(93.2) \\
1(1.4) \\
3(4.1) \\
0 \\
1(1.4)\end{array}$ & $\begin{array}{c}124(93.9 \%) \\
3(2.3 \%) \\
3(2.3 \%) \\
0 \\
2(1.5 \%)\end{array}$ & 0.385 \\
\hline Family history of mental diseases & $8(27.6)$ & $29(48.3)$ & $37(41.6 \%)$ & 0.063 \\
\hline History of substance use & $6(10.2)$ & $14(19.2)$ & $20(15.2 \%)$ & 0.151 \\
\hline Psychiatric comorbidity & $12(20.3)$ & $24(32.9)$ & $36(27.3 \%)$ & 0.108 \\
\hline Other medical diseases & $27(45.8)$ & $30(41.7)$ & $57(43.5 \%)$ & 0.638 \\
\hline Age $($ mean $\pm \mathrm{SD})($ years $)$ & $40.46 \pm 13.64$ & $41.80 \pm 11.32$ & 41.20 & 0.543 \\
\hline
\end{tabular}

employment status, education level, and place of residence $(p>0.05)$. While there was no significant difference between the groups, most of the patients in the RDP group were single (47\%), unemployed (55.3\%), and living with their families $(93.9 \%)$. The mean age of the patients was 40.46 years in the $\mathrm{SH}$ group, and 41.80 in the RDP group. Also, there was no statistically significant difference between the two groups for family history of psychiatric diseases, history of substance use, psychiatric comorbidity, and other medical diseases. The most common physical diseases in the RDP group were chronic obstructive pulmonary disease, atherosclerotic heart diseases, dysrhythmias, and endocrinopathies, while the most in the SH group were neurological diseases and endocrinopathies. The most common psychiatric comorbidities were obsessive-compulsive disorder and substance use disorder in the RDP group, while mental retardation in the $\mathrm{SH}$ group.
The clinical characteristics of the groups are presented in Table 2. The mean number of hospitalizations of the RDP group was $6.18 \pm 3.084$, and the hospitalization period was mean $32.13 \pm 16.74$ days. The most common reason for hospitalization in both groups was the relapse of the disease (SH: 42.4; RDP: 43.8). It was found that in both groups, a majority of hospitalizations were voluntary (SH: 67.8\%; RDP: 58.9\%), and discharges were with partial remission. According to institutes that they followed up at, post-hoc analysis showed that $\mathrm{SH}$ patients were mostly followed up at University outpatient clinic (79.2\%) and most of the RDP patients were followed up at other centers $(46.6 \%)$, and this difference was found to be statistically significant between the groups $(p<0.01)$. In terms of compliance following discharge, the RDP group had significantly less regular follow-up compared to the SH group $\left(\chi^{2}=21.106 \mathrm{p}<0.01\right)$. The most prevalent disease among both groups was 
Table 2. Clinical features of the groups

\begin{tabular}{|c|c|c|c|c|}
\hline & $\begin{array}{c}\text { Single } \\
\text { hospitalization N (59) } \\
\text { N (\%) }\end{array}$ & $\begin{array}{c}\text { Revolving door } \\
\text { phenomenon N (73) } \\
\text { N (\%) }\end{array}$ & $\begin{array}{c}\text { Total } \\
\mathrm{N}\end{array}$ & $P$ \\
\hline Reason for last hospitalization & & & & 0.191 \\
\hline Relapse & $25(42.4)$ & $32(43.8)$ & $57(43.2 \%)$ & \\
\hline Suicide attempt & 0 & $3(4.1)$ & $3(2.3 \%)$ & \\
\hline Violent tendency & $1(1.7)$ & 0 & $1(0.8 \%)$ & \\
\hline Social reasons & $3(5.1)$ & $2(2.7)$ & $5(3.8 \%)$ & \\
\hline Substance use & $1(1.7)$ & $1(1.4)$ & $2(1.5 \%)$ & \\
\hline Drug side effects & 0 & 0 & 0 & \\
\hline Diagnostic evaluation & $2(3.4)$ & 0 & $2(1.5 \%)$ & \\
\hline Non-compliance to treatment & 0 & $4(5.5)$ & $4(3 \%)$ & \\
\hline Multiple reasons & $27(45.8)$ & $31(42.5)$ & $58(43.9 \%)$ & \\
\hline Type of admission & & & & 0.564 \\
\hline Voluntary & $40(67.8)$ & $43(58.9)$ & $83(62.9 \%)$ & \\
\hline Involuntary & $18(30.5)$ & $28(38.4)$ & $46(34.8 \%)$ & \\
\hline Judicial & $1(1.7)$ & $2(2.7)$ & $3(2.3 \%)$ & \\
\hline Outpatient follow-up & & & & $<0.001$ \\
\hline University outpatient clinic & $47(79.7)$ & $33(45.2)$ & $80(60.6 \%)$ & \\
\hline Other centers & $3(5.1)$ & $14(19.2)$ & $17(12.9 \%)$ & \\
\hline Multiple centers & $9(15.3)$ & $6(8.2)$ & $15(11.4 \%)$ & \\
\hline Discharge & & & & 0.312 \\
\hline As is & $3(5.1)$ & $7(9.6)$ & $10(7.6 \%)$ & \\
\hline Partial remission & $56(94.9)$ & $63(86.3)$ & $\begin{array}{c}119 \\
(90.2 \%)\end{array}$ & \\
\hline Referral to upper center & 0 & $2(2.7)$ & $2(1.5 \%)$ & \\
\hline Referral to different department & 0 & $1(1.4)$ & $1(0.8 \%)$ & \\
\hline ECT history & $2(3.4)$ & $23(31.5)$ & $25(18.9)$ & $<0.001$ \\
\hline Treatment regimen & & & & $<0.005$ \\
\hline Monotherapy & $29(49.2)$ & $18(24.7)$ & $47(35.6 \%)$ & \\
\hline Polypharmacy & $30(50.8)$ & $55(75.3)$ & $85(64.4 \%)$ & \\
\hline Clozapine use & $8(13.6)$ & $56(76.7)$ & $64(48.5)$ & $<0.001$ \\
\hline Benzodiazepine abuse & $1(1.7)$ & $5(6.9)$ & $6(4.6)$ & 0.153 \\
\hline Compliance following discharge & $38(64.4)$ & $18(24.7)$ & $56(42.4)$ & $<0.001$ \\
\hline History of suicide attempts & $7(11.9)$ & $31(42.5)$ & $38(28.8)$ & $<0.001$ \\
\hline Final diagnosis & & & & $<0.001$ \\
\hline Schizophrenia & $21(35.6)$ & $46(63)$ & $67(50.8 \%)$ & \\
\hline Acute and transient psychotic disorder & $1(1.7)$ & 0 & $1(0.8 \%)$ & \\
\hline Nonorganic psychosis & $8(13.6)$ & 0 & $8(6.1 \%)$ & \\
\hline Delusional disorder & $4(6.8)$ & 0 & $4(3 \%)$ & \\
\hline Bipolar Affective Disorder & $21(35.6)$ & $16(21.9)$ & $37(28 \%)$ & \\
\hline Schizoaffective Disorder & $4(6.8)$ & $11(15.1)$ & $15(11.4 \%)$ & \\
\hline Change in diagnosis & $23(39)$ & $29(39.7)$ & $52(39.4)$ & 0.931 \\
\hline Violent tendencies & $19(32.2)$ & $35(47.9)$ & $54(40.9)$ & 0.067 \\
\hline Forensic events & $4(6.8)$ & $14(19.2)$ & $18(13.6)$ & $<0.005$ \\
\hline Disability pension & $10(16.9)$ & $20(27.4)$ & $30(22.7)$ & 0.154 \\
\hline Agitation that requires chemical restraint & $35(59.3)$ & $37(51.4)$ & $72(55)$ & 0.364 \\
\hline Drug side effects & $56(94.9)$ & $63(86.3)$ & $119(90.2)$ & 0.099 \\
\hline Age of disease onset (mean $\pm \mathrm{SD}$ ) (years) & $27.55(10.12)$ & $24.11(6.99)$ & 25.63 & $<0.005$ \\
\hline Number of hospitalizations (mean \pm SD) & 1 & $6.18(3.084)$ & 3.86 & $<0.005$ \\
\hline Mean hospitalization duration (mean \pm SD) (days) & $29.12(13.57)$ & $32.13(16.74)$ & 30.78 & 0.256 \\
\hline Mean disease duration (mean $\pm \mathrm{SD})$ (years) & $13.03(9.96)$ & $17.73(9.46)$ & 15.65 & $<0.01$ \\
\hline
\end{tabular}


Table 3. Characteristics of drugs and side effects

\begin{tabular}{|c|c|c|c|c|}
\hline & $\begin{array}{c}\text { Single } \\
\text { hospitalization } \\
\mathrm{N}(\%)\end{array}$ & $\begin{array}{c}\text { Revolving door } \\
\text { phenomenon } \\
\mathrm{N}(\%)\end{array}$ & $\begin{array}{c}\text { Total } \\
\mathrm{N}\end{array}$ & $P$ \\
\hline \multicolumn{5}{|l|}{ Drugs } \\
\hline Typical Antipsychotics & $6(10.2)$ & $5(6.8)$ & $11(8.3 \%)$ & 0.493 \\
\hline Atypical Antipsychotics & $29(49.2)$ & $52(71.2)$ & $81(61.4 \%)$ & $<0.005$ \\
\hline Mood stabilizers & $16(27.1)$ & $27(37)$ & $43(32.6 \%)$ & 0.229 \\
\hline Depot Antipsychotics & $6(10.2)$ & $14(19.2)$ & $20(15.2 \%)$ & 0.151 \\
\hline Antidepressants & $3(5.1)$ & $9(12.3)$ & $12(9.1 \%)$ & 0.150 \\
\hline Benzodiazepines & $2(3.4)$ & $5(6.8)$ & $7(5.3 \%)$ & 0.378 \\
\hline \multicolumn{5}{|l|}{ Drug side effects } \\
\hline Extrapyramidal symptoms & $38(67.9)$ & $43(68.3)$ & $81(68.1 \%)$ & 0.963 \\
\hline Increased prolactin associated side effects & $16(28.6)$ & $8(12.7)$ & $24(20.2 \%)$ & $<0.005$ \\
\hline Metabolic side effects & $24(42.9)$ & $15(23.8)$ & $39(32.8 \%)$ & $<0.005$ \\
\hline Neuroleptic malignant syndrome & 0 & $1(1.6)$ & $1(0.8 \%)$ & 0.344 \\
\hline Intoxication & $1(1.8)$ & $1(1.6)$ & $2(1.7 \%)$ & 0.942 \\
\hline Hematologic side effects & $2(3.6)$ & $3(4.8)$ & $5(4.2 \%)$ & 0.747 \\
\hline Cardiovascular side effects & 0 & $4(6.3)$ & $4(3.4 \%)$ & 0.055 \\
\hline Neurological side effects & $4(7.1)$ & $9(14.3)$ & $13(10.9 \%)$ & 0.212 \\
\hline Other side effects & $35(62.5)$ & $29(46)$ & $64(53.8 \%)$ & 0.072 \\
\hline
\end{tabular}

Table 4. Multiple regression analysis of prognostic factors

\begin{tabular}{lccr}
\hline & $\mathrm{p}$ & $\mathrm{CI} 95 \%$ & OR \\
\hline ECT & 0.144 & $0.584-40.237$ & 4.849 \\
Treatment regimen & 0.002 & $2.282-44.392$ & 10.064 \\
Clozapine use & 0.000 & $12.427-360.466$ & 66.929 \\
Compliance to follow ups & 0.005 & $1.788-25.631$ & 6.770 \\
Suicide attempts & 0.001 & $3.585-102.920$ & 19.210 \\
Forensic events & 0.104 & $0.673-68.849$ & 6.806 \\
Gender & 0.361 & $0.481-7.439$ & 1.893 \\
\hline
\end{tabular}

schizophrenia (SH: 35.6\%; RDP: 63\%), followed by bipolar affective disorder. The mean age of onset was 27.55 in the SH group and 24.11 in the RDP group. It can be said that both groups had onset of disease in their twenties, although disease began earlier in the RDP group. When both groups were compared in terms of the mean duration of disease, there was a significantly longer duration in the RDP group (SH: 13.03; RDP: $17.73, \mathrm{p}<0.01)$.

According to clinical history, the RDP group had significantly higher rates of ECT history, suicidal attempts, multiple drug treatment regimens, history of clozapine use, and forensic events compared to the $\mathrm{SH}$ group $(p<0.01)$. There was no significant difference between the two groups in terms of disability pension, violent tendencies, side effects of the drug, and chemical restraint for agitated behaviors at admission $(\mathrm{p}>0.05)$.

According to characteristics of drug treatments, while there was no significant difference between the two groups according to side effects of drugs; when side effects were examined under subdimensions, the $\mathrm{SH}$ patients had higher rates of elevated prolactin level associated side effects like amenorrhea, loss of sexual desire and metabolic side effects like weight gain, hyperglycemia $(p<0.01)$. In patients with combined antipsychotic use, the prevalence of atypical antipsychotic use was significantly higher in the RDP group $(p<0.05)$. Data related to drug use and side effects are presented in Table 3.

Multiple regression analysis revealed that a history of ECT, suicide attempts, multiple drug use in the treatment regimen, clozapine use, and compliance to follow up after discharge had prognostic value in predicting frequent hospitalizations. Male gender did not yield statistical significance in predicting frequent hospitalizations. The data is presented in Table 4.

\section{DISCUSSION}

The results of this study indicate that Turkey also has RDP patients with characteristics and hospitalization patterns similar to patients in countries with different cultural, social, and economic conditions (Morlino et al. 2011, Frick et al. 2013, Botha et al. 2010). Noncompliance with follow-up, male gender, multiple drug 
regimen, suicide attempts, and presence of forensic events were found to be more prevalent in the RDP group than in patients with single hospitalization, as consistent with other studies (Morlino et al. 2011, Botha et al. 2010, Gastal et al. 2000). However, in terms of the tendency to violence, depot antipsychotic use, unemployment, and lack of family support, which were reported to be more prevalent in patients with frequent hospitalizations (Di Lorenzo et al. 2016, Botha et al. 2010, Weiden \& Glazer 1997, Morlino et al. 2011, Goodpastor \& Hare 1991, Haywood et al. 1995), our study found no significant difference between RDP and SH patients.

In our study, most RDP patients were male, single, unemployed despite education level above high school, and living with their families. However, there was no difference between the groups in terms of variables other than gender. In Turkey, there are no protective workplaces for vulnerable groups such as psychiatric patients and these individuals have difficulty in finding jobs (Kayıhan \& Köse 2018, Bilge et al. 2016). Therefore, unlike other studies, unemployment may not differ between groups. Similarly, unlike existing studies, patients' living environment does not differ between groups. This finding may be due to the stronger family relationships in Turkey than in other countries. On the other hand, in Turkey, people often live with their parents until they get married, unlike Western societies. The high level of education in both groups is a striking finding, which may be related to the existence of compulsory education for at least 8 years in Turkey. Therefore, these findings suggest that the diseaserelated variables were more effective in the case of frequent hospitalizations.

The substance use history did not make any difference between the groups. When looking at other studies, substance abuse was more reported in the RDP group (Botha et al. 2010, Kim et al. 2011). On the other hand, among these patients, $13(17.81 \%)$ patients in the RDP group and $2(3.39 \%)$ patients in the SH group only met the criteria for alcohol or substance addiction according to ICD-10. Alcohol and substance addiction rates were lower in both groups compared to similar studies (Botha et al. 2010, Romer Thomsen et al. 2018). This may be related to the relatively low rates of comorbid substance use of psychotic patients in Turkey or the fact that marijuana and other substance usage are not questioned enough or are kept secret. Substance screening tests are not routinely performed on psychotic patients in Turkey.

When disease-related factors are examined, it was observed that the RDP group did not comply with follow-up after discharge and multiple drug use was also more prevalent among these patients. In addition to using more than one drug, the usage of atypical antipsychotics was also more prevalent among RDP patients. This finding may be related to the fact that atypical antipsychotics are generally more preferred in treatment.
In the studies conducted, conflicting results were found about the effectiveness of different antipsychotics on hospitalization frequency. While atypical antipsychotics were found to be superior in the study conducted by Conley et al., in a research conducted by Gültekin et al. with 292 patients, no difference was found between the patients with recurrent hospitalizations and single hospitalization (Conley et al. 2003; Gültekin et al. 2013b). In another study with 1-year follow-up, a decrease in the frequency of hospitalizations was observed only in patients using clozapine among treatments of typical, atypical antipsychotics and clozapine (Valevski et al. 2012). In our study, although both clozapine and other atypical antipsychotics were used more in the RDP group, the high frequency of hospitalization may be related to non-compliance with treatment or the refractory clinical course. However, in our study, non-compliance with treatment or disease severity could not be directly evaluated. Because in the retrospective study design, it was thought that the interrater validity among the physicians who scored the scales to evaluate the disease severity or treatment compliance would not be consistent. Besides, outpatient rehabilitation after discharge and lack of a regular follow-up system may also play a role in Turkey.

In addition, the literature also reports that depot antipsychotic use reduced the frequency of hospitalizations (Gutwinski et al. 2007, Novick et al. 2010, Botha et al. 2010). In our study, no difference was found between the groups in terms of depot antipsychotic use. In Turkey, since the atypical depot antipsychotics did not take place in the market mainly in the range of 20112016, typical depot antipsychotics may have been preferred more, and the extrapyramidal side effects that occur with these drugs may have limited their use.

Since multiple drug use is one of the factors that disrupt patient compliance, simplifying drug treatments as much as possible may be helpful in both reducing side effects, and improving impaired quality of life (Kane 2005, Centorrino et al. 2004, Längle et al. 2012). In our study, it was found that polypharmacy was used more in the treatment regimens in the RDP group, but side effects such as hyperglycemia, weight gain, loss of sexual desire, and amenorrhea were more frequently reported in the $\mathrm{SH}$ patients. Whereas, patients in the RDP group received significantly more atypical antipsychotic treatments than SH patients. Maybe, patients with more intense negative symptoms and more deterioration may have been included in the RDP group, and these patients may not have reported side effects, most of which were subjective, or their families may not be aware of them. Besides, as these patients are considered as chronic cases, physicians' interest in side effects may have decreased. On the other hand, it is difficult to make a definite interpretation because all the drug treatments that patients have taken in the past were not known. 
In the study, voluntary hospitalization was higher in both groups, and there was no difference in terms of hospitalization type. Unlike other studies, there are very few hospitalizations for judicial reasons, since our inpatient clinic is not a closed service, the courts mostly direct judicial hospitalizations to different units. In some studies, it has been reported that voluntary hospitalization is more common in patients with recurrent hospitalizations, and this is used by patients as a social support mechanism (Oyffe et al. 2009, Di Lorenzo et al. 2016).

According to institutes where the patients were followed up, the RDP group had significantly higher rates of follow up at institutes other than the University outpatient clinic $(p<0.01)$. While patients who were followed up at external clinics did not imply they had irregular follow up, a majority of patients with single hospitalization were followed up at a single clinic, which may provide insight into the patient's compliance to treatment. On the other hand, disease severity-resistance status may cause patients/relatives to seek further treatment, which may be why they applied to more than one clinic.

In our study, the final diagnosis was schizophrenia in $63 \%$, followed by bipolar affective disorder in $21.9 \%$, and schizoaffective disorder in $15.3 \%$ of RDP patients. Schizophrenia was generally reported as the most common diagnosis for cause of frequent hospitalizations (Gastal et al. 2000, Clemmensen et al. 2012, Haywood et al. 1995, Goodpastor \& Hare 1991). There was no difference between the groups in terms of a specific diagnosis, and there was no difference in diagnosis change in the follow-up.

The mean hospitalization time was 29.12 in SH patients and 32.13 in RDP patients $(\mathrm{p}>0.01)$. While there was no significant difference between the groups according to hospitalization duration, it could be said that this mean time period is relatively short for patients with chronic mental diseases. In recent years, due to the transition from hospital-based healthcare services to community-based healthcare services and the reduced number of beds, the length of hospitalization of patients has been shortened, and patients often have to be discharged early before full recovery. Some researchers indicate that early discharge causes recurrent hospitalizations (Botha et al. 2010). According to 2017 Turkish data, the total number of psychiatric ward beds were 7115 , the total number of hospitalizations in one year was 9,493,097, and the number of CMHC was 163 (Public Hospitals Statistics Report 2017). Considering the Turkish population of 80 million people, it can be observed that the number of beds in comparison with the number of psychiatric admissions is insufficient, which also leads to the early discharge of patients. By providing an area outside the home or hospital through CMHCs to treat chronic mental diseases, it is aimed to provide a rehabilitation period outside the hospital following acute treatment and regain patients into society. Although this treatment approach has been successful in some countries, the fact that the number of beds was reduced before attaining a sufficient number of CMHCs in Turkey leads to a shortened hospital stay and increased drug-oriented treatments for the relief of acute symptoms, and therefore, inadequate benefit from long-term rehabilitation services. Although the number of CMHC is insufficient, it is seen that regional successes have been achieved in decreasing the frequency of hospitalizations in studies (Aydın et al. 2014). Lack of a Gazi University affiliated CMHC unit may have caused RDP by increasing the hospitalization frequency of some patients.

The main limitation of this study is the high number of patients who could not be included in the study due to the limited data. Since a large number of patients were excluded from the study, some data could not be compared, and some did not reach a level of significance regardless of comparison. In general, more valid results can be obtained by improving the registration systems, such as forming a database where the data of the patients can be accessed throughout the entire country. Another limitation is that there are no scale evaluations with interrater validity in the study. Disease severity, which is one of the most important variables associated with recurrent hospitalizations, could not be evaluated for this reason. Other limitations are that antipsychotic equivalent doses cannot be compared, other social variables that may affect hospitalization processes have not been evaluated, and some variables are only evaluated based on statements. However, although the number of studies conducted in our country on this subject is few, retrospective evaluation of this 5-year period, and including a control group of patients with single hospitalization were among the strengths of the study. Another strength of the study is the stricter criteria in the RDP inclusion. Thus, it was aimed to investigate patients who cause more burden on the health system and have more frequent relapses.

\section{CONCLUSION}

Despite the difficulties in conducting a study on this subject, identifying the factors that cause frequent hospitalizations with prospectively designed studies will not only benefit the patient but also decrease the health system burden. Future studies in this area should focus on longitudinal follow-up, with tools to more directly assess disease severity and treatment non-compliance. In addition, home visits to evaluate the social environment of the patients will allow a more holistic approach to evaluating hospitalization frequency. It is thought that outpatient follow-up at CMHCs after inpatient treatment is important in preventing the revolving door phenomenon. Therefore it is necessary to further improvement of the CMHCs in Turkey. 
Acknowledgments: None.

\section{Conflict of interest: None to declare.}

\section{Contribution of individual authors:}

Buket Koparal \& Mehmet Ünler: study design, data collection, search for literature, writing the paper.

Hayriye Çisem Utku: study design, statistical analysis.

Selçuk Candansayar: study design.

All authors reviewed the final manuscript and gave their consent for the final version.

\section{References}

1. Aydın E, Tabo A, Karamustafalıŏlu KO, Alataş G, Yiğit S, Aydin E, et al: Döner kapı olgusu: Toplum temelli ruh sağllğı hizmet modeline geçişin psikiyatri servisine yatış üzerine etkisi. Anatolian Journal of Psychiatry 2014; 15:185-191

2. Bilge A, Mermer G, Çetinkaya A, Erdoğan E, Üçkuyu N: Türkiye'deki toplum ruh sağllğg merkezlerinin 2013-2015 yillarının profili. Kocaeli Üniversitesi Sağllk Bilimleri Dergisi 2016; 2:1-5

3. Botha UA, Koen L, Joska JA, Parker JS, Horn N, Hering $L M$, et al: The revolving door phenomenon in psychiatry: comparing low-frequency and high-frequency users of psychiatric inpatient services in a developing country. Soc Psychiatry Psychiatr Epidemiol 2010; 45:461-468

4. Centorrino F, Goren J, Hennen J, Salvatore P, Kelleher J, Baldessarini $R$ : Multiple versus single antipsychotic agents for hospitalized psychiatric patients: case-control study of risks versus benefits. Am J Psychiatry 2004; 161:700-706

5. Clemmensen L, Vernal DL, Steinhausen HC: A systematic review of the long-term outcome of early-onset schizophrenia. BMJ Psychiatry 2012; 12:150

6. Conley RR, Kelly DL, Love RC, McMahon RP: Rehospitalization risk with second-generation and depot antipsychotics. Annals of clinical psychiatry 2003; 15:23-31

7. da Graça Cantarelli M, Nardin P, Buffon A, Eidt MC, Antônio Godoy L, Fernandes BS, et al: Serum triglycerides, but not cholesterol or leptin, are decreased in suicide attempters with mood disorders. J Affect Disord 2014; 172C:403-9

8. Di Lorenzo R, Sagona M, Landi G, Martire L, Piemonte $C$, Del Giovane C: The Revolving Door Phenomenon in an Italian Acute Psychiatric Ward: A 5-Year Retrospective Analysis of the Potential Risk Factors. J Nerv Ment Dis 2016; 204:686-692

9. Frick $U$, Frick H, Langguth B, Landgrebe M, HubnerLiebermann B, Hajak $G$ : The revolving door phenomenon revisited: time to readmission in 17'145 [corrected] patients with 37'697 hospitalisations at a German psychiatric hospital. PLoS One 2013; 8:e75612

10. Gastal FL, Andreoli SB, Quintana MI, Almeida Gameiro $M$, Leite SO, McGrath J: Predicting the revolving door phenomenon among patients with schizophrenic, affective disorders and non-organic psychoses. Rev Saude Publica 2000; 34:280-285
11. Goodpastor WA \& Hare BK: Factors associated with multiple readmissions to an urban public psychiatric hospital. Hosp Community Psychiatry 1991; 42:85-87

12. Gutwinski S, Muller P, Koller M: Intervals between hospitalisations in schizophrenia patients under antipsychotics in depot-form versus oral second generation antipsychotics. Psychiatr Prax 2007; 34:289-291

13. Gultekin BK, Kesebir Ş, Gulucu A, Ergelen M: Frequency and Predictors of Recurrent Hospitalizations of Schizophrenic Patients. Clinical Psychiatry 2013a; 16:225-231

14. Gultekin BK, Kesebir Ş, Irmak Ç, Kucuksubaşı Y: Rehospitalization Rates of Patients with Schizophrenia Discharged on Typical, Atypical Antipsychotics, Electroconvulsive Therapy or Combination Treatment During Six Months. Clinical Psychiatry 2013b; 16:206-213

15. Haywood TW, Kravitz HM, Grossman LS, Cavanaugh JL, Jr Davis JM, Lewis DA: Predicting the "revolving door" phenomenon among patients with schizophrenic, schizoaffective, and affective disorders. Am J Psychiatry 1995; 152:856-861

16. Kane JM: Management of patients with treatment-resistant schizophrenia, 128-129. In: Kane JM (eds): Optimizing Pharmacotherapy to Maximize Outcome in Schizophrenia [Academic Highlights]. J Clin Psychiatry 2005: 66:122-133

17. Kastrup M: Who became revolving door patients? Findings from a nation-wide cohort of first time admitted psychiatric patients. Acta Psychiatrica Scandinavica 1987; 76:80-88

18. Kayıhan $H$ \& Köse B: Türkiye'de ve dünyada mesleki rehabilitasyon. Turkiye Klinikleri Psychology-Special Topics 2018: 3:30-41

19. Kim HM, Pfeiffer P, Ganoczy D, Valenstein M: Intensity of outpatient monitoring after discharge and psychiatric rehospitalization of veterans with depression. Psychiatr Serv 2011; 62:1346-1352

20. Korkeila JA, Lehtinen V, Tuori T, Helenius H: Regional differences in the use of psychiatric hospital beds in Finland: a national case-register study. Acta Psychiatr Scand 1998; 98:193-199

21. Längle $G$, Steinert $T$, Weiser $P$, Schepp $W$, Jaeger $S$, Pfiffner C, et al: Effects of polypharmacy on outcome in patients with schizophrenia in routine psychiatric treatment. Acta psychiatrica scandinavica 2012; 125:372-381

22. Lay B, Lauber C, Rossler W: Prediction of in-patient use in first-admitted patients with psychosis. Eur Psychiatry 2006; 21:401-409

23. Lewis $T$ \& Joyce PR: The new revolving-door patients: results from a national cohort of first admissions. Acta Psychiatrica Scandinavica 1990; 82:130-135

24. Lichtenberg P, Levinson D, Sharshevsky Y, Feldman D, Lachman M: Clinical case management of revolving door patients - a semi-randomized study. Acta Psychiatr Scand 2008; 117:449-454

25. Montgomery $P \&$ Kirkpatrick H: Understanding those who seek frequent psychiatric hospitalizations. Arch Psychiatr Nurs 2002; 16:16-24

26. Morlino M, Calento A, Schiavone V, Santone G, Picardi $A$, de Girolamo $G$ : Use of psychiatric inpatient services by heavy users: findings from a national survey in Italy. Eur Psychiatry 2011; 26:252-259

27. Moss J, Li A, Tobin J, Weinstein IS, Harimoto T, Lanctot KL: Predictors of readmission to a psychiatry inpatient unit. Compr Psychiatry 2014;55, 426-430 
28. Novick D, Haro JM, Suarez D, Perez V, Dittmann RW, Haddad PM: Predictors and clinical consequences of nonadherence with antipsychotic medication in the outpatient treatment of schizophrenia. Psychiatry Res 2010; 176:109-113

29. Oyffe I, Kurs R, Gelkopf M, Melamed Y, Bleich A: Revolving-door patients in a public psychiatric hospital in Israel: cross sectional study. Croat Med J 2009; 50:575582

30. Public Hospitals Statistics Report 2017. Accessed February, 05, 2020.

https://dosyamerkez.saglik.gov.tr/Eklenti/21853,kamuhastaneleri-istatistik-raporu--2017pdf.pdf?0

31. Roick C, Heider D, Kilian R, Matschinger H, Toumi M, Angermeyer MC: Factors contributing to frequent use of psychiatric inpatient services by schizophrenia patients. Soc Psychiatry Psychiatr Epidemiol 2004; 39:744-751

32. Romer Thomsen K, Thylstrup B, Pedersen MM, Pedersen MU, Simonsen E, Hesse M: Drug-related predictors of readmission for schizophrenia among patients admitted to treatment for drug use disorders. Schizophr Res 2018; 195:495-500

33. Valevski A, Gilat $Y$, Olfson M, Benaroya-Milshtein $N$, Weizman A: Antipsychotic monotherapy and adjuvant psychotropic therapies in schizophrenia patients: effect on time to readmission. International clinical psychopharmacology 2012; 27:159-164

34. Weiden P \& Glazer W: Assessment and treatment selection for "revolving door" inpatients with schizophrenia. Psychiatr Q 1997; 68:377-392

Correspondence:

Buket Koparal, MD

Recep Tayyip Erdoğan University Training and Research Hospital, Psychiatry Clinic Rize, Turkey

E-mail:bkt_svnc@hotmail.com 